literarios y filológicos sobre los que debatió, sin respuestas afortunadas, un siglo de crítica literaria.

En suma, esta edición dista mucho de ser la que la obra merece y la que cabría esperar en 1982.

ANA VIAN

Universidad Complutense de Madrid

\title{
LA MADRE JUANA DE LA CRUZ (1481-1534) \\ Y LA CUESTIÓN DE LA AUTORIDAD REIIGIOSA FEMENINA
}

La Madre Juana de la Cruz fue hija de Catalina Gutiérez y Juan Vázquez, modestos labradores del pequeño pueblo de Azaña, en el arzobispado de Toledo. Desde niña iuvo visiones y revelaciones ${ }^{1}$. Se hizo monja franciscana en el convento de Santa María de la Cruz (cerca de Cubas), del cual llegó a ser abadesa. Durante sus éxtasis pronunciaba sermones que atraían mucho público; llegó a tener entre sus oyentes al cardenal Cisneros, al Gran Capitán y al propio Carlos $\mathrm{V}^{2}$. La pregunta que se impone es: ¿cómo una mujer de tan humilde cuna llegó a gozar de semejante autoridad espiritual ante las figuras más destacadas de la España de su época?

Cabe observar, ante todo, que el período de Cisneros fue un momento histórico muy propicio para místicos y visionarios de toda laya, y especialmente para las mujeres ${ }^{3}$. En esa época impregnada de mesianismo se prestó mucha atención a las visiones y profecías procedentes de mujeres. Las mujeres-videntes tenían prestigio, y los fenómenos extraordinarios experimentados por ellas

Sobre el fenómeno de las visiones místicas ef. ERNST BEN, Die Vision (Ernst Kleti Ver lag, Stuttgart, 1969) y PeTer Dinzelbacher, Vision un Visionsliteratur im Mittelalter (Anton Hiersemann, Stuttgart, 1981).

2 Fray ANTONIO DAZA, Historia, vida y milagros, éxtasis y revelaciones de la bienaitenturada virgen santa Juana de la Cruz, Madrid, 1610 , fol. $58 \mathrm{v}$

3 Las apariciones a seglares (y sobre todo a mujeres) abundan en el siglo xv y en los primeros años deI XVI. La muerte de Cisneros en 1517 coincide más o menos con el momento en que los papas y la Inquisición española deciden examinar con mayor rigor el caso de los visionarios laicos. Véase sobre esto William A. Christian, $\}_{R}$., Apparitions in Late Medieval and Renaissance Spain, Princeton University Press, Princeton, 1981, pp. 150-151. El fenómeno del florecimiento de los visionarios bajo Cisneros está a tono con el ambiente mesiánico en que se movían los Reyes Católicos. En parte, ese mesianismo era fomentado por los propagandistas de los monarcas. Véase Américo CaStro, Aspectos dei vivir hispánico, Alianza, Madrid, 1970, pp. 13-45, y José Cepeda ADÁn, "El providencialismo en los cronistas de los Reyes Católicos", Arb, 17 (1950), 177-190. Pero lo que en un momento pudo ser propaganda oficial llegó a contagiar los sueños de toda una generación. Cisneros y Colón soñaban con la conquista de Jerusalén por los Reyes Católicos. A los factores político-religiosos hay que agregar la exacerbación de la sensibilidad religiosa, fenómeno general en la Europa de fines del siglo xv, estudiado por Huizinga y otros autores. En España se relaciona con la difusión de obras de espiritualidad mediante la imprenta y con la reforma de las órdenes religiosas emprendida por Cisneros y auspiciada por los monarcas. Un fruto de ese inmenso anhelo de lo divino fue la búsqueda de nuevas formas con que expresarlo. El fenómeno de los visionarios respondía a las necesidades psicológicas de aquellos creyentes que, insatisfechos de la mediación ofrecida por el clero, buscaban un modo más directo de ponerse en contacto con la divinidad. El vidente funcionaba como un locus de poder espiritual, un canal de gracia. 
tenían un aura de gran autoridad. No es raro que Cisneros, hombre de sus tiempos, las haya tomado tan en serio ${ }^{4}$. Se concedía una acogida fervorosa al misticismo, es decir, a un tipo de mediación religiosa no intelectual (ni tampoco institucional) en que, tradicionalmente, la mujer había tenido campo para afirmarse ${ }^{5}$. Pero el que la Madre Juana haya gozado de protección oficial no significa que su persona y sus visiones merecieran aprobación general. Los pocos hechos conocidos por la Vida de la monja y los datos indirectos suministrados por sus escritos nos pintan a una mujer de autoridad a veces ambigua, una mujer a quien algunos miraban con recelo.

El prestigio de la Madre Juana está bien confirmado por uno de los pocos documentos históricos relacionables con su vida. Me refiero al extraño episodio de aquel visicnario franciscano que, creyéndose destinado a engendrar una especie de mesías, le escribió en 1512 a la Madre Juana invisándola a ser su "colaboradora". (Por toda respuesta, la monja to cienunció al custodio de Toledo, y éste, a su vez, a Cisneros). Semejante episodio nos muestra bien el haz y el envés de la condición de visionaria de la Madre Juana. El anónimo franciscano, movido sin duda por la fama mística de la monja (no tenemos por qué especular acerca de sus apetitos biológicos), estaba seguro de haber encontrado la candidata ideal para sus altísimos propósitos. Ella, por su parte, se mantuvo hija fiel de la Iglesia, y eso a pesar de lo que parecían prometer los favores celestiales de que gozaba. Es decir, el sujeto de los fenómenos extraordinarios era una creyente ordinaria y ortodoxa que no se dejó seducir por las proposiciones tan lisonjeras como atrevidas del iluso fraile.

Un segundo episodio parece indicar que si a las mujeres se les permitía el papel de videntes, no se les toleraba que ocuparan puestos de poder en la jerarquía eclesiástica. Entre los escasos documentos históricos que atañen a la Madre Juana hay dos rescriptos de Cisneros, uno de 9 de marzo de 1510 y otro de 28 de diciembre del mismo año. Su contenido es casi igual: son respuesta a una petición del párroco de Cubas, el cual, por haber conseguido otra parroquia, solicita que la que él deja se anexe al convento de Santa María de la Cruz (del cual es abadesa la Madre Juana); Cisneros otorga lo pedido, pues se trata de un modo eficaz de remediar la pobreza del convento y evitar así que unas monjas de clausura tengan que recurrir a ia mendicidad ${ }^{7}$. Así, pues,

4 Para las relaciones de Cisneros con las beatas cî. Marcel Batalllon, Erasmo y España, trad. A. Alatorre, $2^{a}$ ed., F.C.E., México, 1966, pp. 68-71, y Álvaro Huerga, O. P., "Los pre-alumbrados y la Beata de Piedrahita", apud. Fliche-MARTIN, Historia de la Iglesia, t. 17, EDICEP, Valencia, 1974, pp. 523-546.

5 En un lugar de la Summa Theologica (suplemento de la parte III, q. 39, art. 1), Santo Tomás le niega a la mujer la función sacerdotal, pero le permite el papel de profetisa: "Ad primum ergo dicendum quod prophetia non est sacramentum, sed Dei donum. Unde ibi non exigitur significatio, sed solum res. Et quica secundum rem in his quae sunt animae mulier non differt a viro, cum quandoque mulier invematur melior quantum ad animam viris multis, ideo donum prophetiae et alia huiusmodi potest recipere, sedi non ordinis sacramentum".

6 El custodio de Toledo, fray Antonio de Pastrana, es quien cuenta la historia en una carta a Cisneros (1512) publicada por Manuel Serrano y SAnZ, "Pedro Ruiz de Alcaraz, iluminado alcarreño del siglo XVI", RABM, 8(1903), p. 2. Fray Antonio de Pastrana caracteriza a su hermano de hábito como "religioso contenplativo alumbrado con las tinieblas de Satanás", - -primera vez (dice BATAILlon, op. cit., p. 68) que aparece el calificativo de alumbrado "aplicado a un franciscano",

7 JOSÉ Luis DOmínguez Ruiz, El cardenal Cisneros y el monasterio de Santa María de la Cruz, tesis de la Facultad de Derecho Canónico de la Universidad Pontificia de Comillas, 1974, incluye en las pp. 25-37 una reproducción fotográfica de la copia que se hizo en el siglo xvinl de los res- 
las monjas adquieren el usufructo de los bienes de la parroquia y pueden nom* brar un capellán que atienda a las necesidades espirituales de los feligreses.

Sin duda es éste un caso muy raro. Se plartea, nada menos, el problema de si las mujeres pueden ejercer jurisdicción espiritual. Y también cabe preguntar si Cisneros tenía o no autoridad para otorgar semejante privilegio ${ }^{8}$. El hecho es que, muerto Cisneros (1517), algunos eclesiásticos intentaron quitarles a las monjas de Santa María de la Cruz el beneficio de Cubas, argumentando que "las mugeres, aunque fuesen religiosas, no heran sufiçientes para ser cura de ánimas de personas seglares". . La Madre Juana, siempre celosa del bienestar económico del convento, acudió a otros eclesiásticos, los cuales le aconsejaron pedir una bula papal que confirmara "persona sufiçiente para estar en el servicio del curado por el monasterio". Así lo hizo ella, y entonces la madre vicaria, enemiga suya, la denunció ante las autoridades de la orden de San Francisco, diciendo que habia actuado sin las debidas licencias y exa gerando la cantidad de dnero que se habia gastado en conseguir la bula. El asunto se complicaba por el hecho de que el clérigo que a la sazón ocupaba el curato de Cubas era hermano carnal de la Madre Juana. De resultas de todo ello, las autoridades de la orden seráfica le quitaron a la acusada su puesto de abadesa y se lo dieron a la madre vicaria ${ }^{10}$.

Con el tiempo, la Madre Juana quedó reivindicada. La nueva abadesa cayó enferma de gravedad y, habiendo convocado a las monjas y al vicario, les confesó que había procedido injustamente en su delación (Vida, fol. 98v). Pero, prescindiendo de los resultados que haya tenido el asunto de la bula, el episodio demuestra hasta qué punto era problemática la concesión de facultades extraordinarias a una mujer, por excepcional que ésta haya sido. Se trataba, de hecho, de un problema de poder. Y, pese al precedente de la abadesa de Las Muelgas, que gozaba de un privilegio de índole análoga ${ }^{11}$, es evidente la resistencia a aceptar que una mujer ejerciera jurisdicciones que se consideraban privativas de eclesiásticos varones. Los rescriptos de Cisneros - como observa DOMínGUEZ RUIZ, p. 68- no dicen que la abadesa tuviera que hacer confirmar por las autoridades eclesiásticas al candidato escogido por ella para el curato de Cubas. Sin embargo, así parece haberse hecho: la Vida manuscrita dice (fol. 78r) que el hermano de la abadesa ya "residía en el curado, puesto por mano y voluntad de los perlados, porque hera persona suficiente y aparejado a toda virtud, y el pueblo estava contento dél'". Esto quiere decir

criptos originales. (Le agradezco al P. Jesús Gómez López el haberme obsequiado una fotocopia de esa tesis.)

8 Sobre el aspecto jurídico de los rescriptos véase la mencionada tesis de Domínguez Ruiz, pp. $70-88$

9 Vida y fin de la bionabeniurada virgen sancla Juana de la Cruz, biblioteca del Escorial, ms. K-III13, fol. $77 \mathrm{v}$. - En todas mis transcripciones modernizo acentuación, puntuación y uso de mayúsculas, regularizo el empleo de $u / v$ y de $i / j$, represento con $e$ la conjunción copulativa, transcribo como $r$ la $r$ - inicial y la -rr-después de consonante, y resuelvo las abreviaturas.

10 Según fray ANTONIo DaZA, op. cit., fol. 88v, la destitución ocurrió en 1527. En otro lugar (fol. 67v) dice que la Madre Juana fue abadesa durante 17 años continuos. Según eso, comenzó a ser abadesa en 1510. Sin embargo, al hablar de su elección como abadesa, el mismo biógrafo dice (fol. 67r) que en ese momento la monja tenía 27 o 28 años, lo cual significaría que la elección tuvo lugar en 1508 o 1509. En todo caso, los rescriptos de Cisneros corresponden a los primeros años de actividad de la Madre Juana como abadesa.

11 Véase José María Escrivá, La abadesa de Las Huelgas, Editorial Luz, Madrid, 1944, pp. 120-121. 
que, aun antes de que se cuestionara el derecho al beneficio de Cubas, la abadesa no gozaba de poderes ilimitados sobre él, según parecían garantizárselo los rescriptos de Cisneros. El hecho mismo de que el cardenal haya tenido que firmar dos rescriptos de contenido casi idéntico dentro de un solo año permite imaginar que hubo oposición al primer rescripto y que se hizo necesario el segundo. En todo caso, parece evidente que, a pesar de la voluntad de Cisneros, hubo eclesiásticos que hicieron lo posible por limitar la autoridad de la monja.

Parecida ambigüedad en cuanto a la autoridad se manifiesta también, aunque de modo oblicuo, en el caso de los escritos de la Madre Juana. A lo largo de trece años, nuestra monja creyó que Dios se revelaba a través de ella "por boca del Espíritu Santo. . . en persona de Nuestro Señor Jesuchristo"12. Estas revelaciones suyas se denominan "sermones". No se conocen sino los "sermones" de 1509, tomados al dictado por otra monja. La compilación se inti. tula El libra del conorte, y constuye la única obra txiste de la Madre Juana. Por lo general, los sermones consisten en la descripcion de las representacio nes y celebraciones que tienen lugar en tcielo para solemnizar las fiestas principales del año litúrgico. Las descripciones van entreveradas con interpretaciones espirituales y tropológicas que atañen a la salvación del alma. A veces, la vidente intercala réplicas a los reparos - reales o imaginarios-- relativos a la inspiración divina de las revelaciones y a la condición de mujer de la vidente ${ }^{13}$.

El propio Cristo parece explicar, desde el texto del Libro del conorte, el porqué de las revelaciones. En el sermón para la fiesta de la Santa Cruz dice que ha determinado revelarse así en estos tiempos por la gran necesidad que hay de su doctrina:

. . viendo Él cómo se perdía Dios en la ticrra e se perdían la fe y el amor y caridad con Él e con los próximos, e viendo quán sin reverençia es tratado en el Sacramento, e viendo las grandes eregías e abominaçiones, demandó licençia al Padre celestial para venir a fablar en esia boz. . . E assi ienía Él por bien de venir a lablar en esta boz para que le oyesen buenos e malos, e dudosos e creyentes. . No quería fazer, quando venía a lablar en esta boz, otros miraglos ni maravillas sino dezirnos e declararnos todo lo que nos cunplía para nuestra salvaçión, e corregirnos e reprehendernos de lo que errávamos e ofendíamos contra su divina magestad (Conorte, fols. $278 \mathrm{v}$ y $279 \mathrm{r}$ ).

12 El libro del conorte, bibl. del Escorial, ms. J-II-18, fol. 8r.

13 Las mujeres solían afirmar la autenticidad de sus revelaciones desde el texto mismo que escribían. Matilde de Magdeburgo (m. 1282) declara simplemente que su inspiración viene del Espíritu Santo: "Ich cnkan noch mag nit schriben, ich sehe es mit den ogen mmer sele und höre es mit den oren mines ewigen geiste: und bevinde es in alken hden mines lichamen die kraft des heiligen gcistes" (Offenbarungen der Schwester Mechthild von Magdeburg oder Das fliessende Licht der Goltheit, ed. P. Gall Morel [1369], reimpr., Wissenschaftliche Buchgesellschaft, Darmstadt, 1963, p. 107) En otros casos, Dios mismo es el ratificador. "Ecce dedi verba mea in ore tuo, et confirmo m veritate mea omnia verba quaecumque, instigante spiritu meo. . .", le dice Él a Santa Gertrudis de Helfa (m. 1302) (Oeuvres spirituelles, t. 2, ed. Pierre Doyère, Éditions du Cerf, Paris, 1968, p. 198). Santa Ángela de Foligno transcribe estas palabras que Dios le dijo: "Totum illud quod scriptum est, totum scriptum cst secundum uoluntatem meam. Et a me uenit, id est, a me processit" (Le livre de la bienheureuse Angèle de Foligno, Texte latin, ed. Paul Doncour, Art Catholique, Paris, \& Revuc d'Ascétique et de Mystique, Toulouse, 1925, p. 99). Y a Santa Brígida (m. 1373) le dice Crisı: "ítaque ego ipse Deus sum, qui clamo. Verba mea, que tu in spirituali visione frequenter a me audis, saciant quasi bonus potus sicientes veram caritatem"' (Revelaciones, lib. V, ed. Birger Bergh, Almqvisı \& Wiksells, Uppsala, 1971, p. 163). 
Pero ¿cómo saber que es Cristo quien habla por mediación de la monja? El sermón VIII establece como criterio la virtud o malicia del oyente: "E dixo el Señor que las personas devotas que tuvieren algún amor con Él, o algunos gustos de sus dulcedunbres, conosçerán luego cómo todas estas palabras son divinales e dichas por su sagrada boca; e los que tuvieren el ojo de la intinçión dañado, que no sabrán gustar a Dios ni conosçer sus verdaderas palabras e dulcedunbres" (Conorte, fols. 76v-77r). Lo cual constituye una estratagema tan sencilla como ingeniosa: si los buenos reconocían que las palabras de la monja eran de origen divino y los malintencionados no, ello quería decir que quienes creían en la inspiración divina de los sermones podían contarse entre los amigos de Dios, mientras que los incrédulos podían contarse entre los malos ${ }^{i 4}$

¿Y si fuera el demonio el inspirador de los sermones? Sólo una vez se plantea esta cuestión en el Libro del conorte. Desde luego, la autora no parece haber cono-

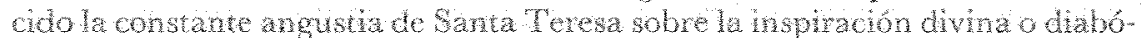
lica de sus visiones ${ }^{15}$. En el sermón sobre la parabola del sembrador, Dios mismo refuta a los incrédulos:

E si dizen que el demonio se trasfigura en ángel de luz para hazer o dezir algunas cosas, que responde Él mesmo como Dios e Señor e dize que, como Satanás sea su enemigo, nunca enseña a nadie que ame a Dios; e como sea muy cruel, nunca enseña a nadie caridad verdadera; e como sea en sí muy triste e lleno de tormentos e fuego, nunca enseña a nadie alegría ni gozo de espíritu; e como sea todo malo, nunca puede dar a nadie graçia ni lunbre verdadera para amar e creer e conosçer la verdad e lo çierto (Conorte, fol. 104v).

No sólo se concluye que Satanás no puede ser el inspirador, sino que se encarece la bondad de los sermones, con su mensaje de caridad y gozo espiritual. ¿Y por qué ha querido Dios hablar por boca de "una muger pobre e pequeña"? También a esta pregunta se contesta desde dentro del Libro. En primer lugar Dios es Dios y puede hacer cuanto quiera, y no niega su misericordia a nadie que lo ame y con fervor lo busque, que es lo que hace "esta su sierva" (fol. 76v). En segundo lugar, cuando es voluntad suya que se escriban algunos de sus secretos, poco importa si los redactores de sus sagradas palabras son hombres o mujeres. Dios mismo cita casos pertinentes: "Porque tanbién quiso Él ser atestiguado de mugeres como de honbres en la su gloriosa Resurreçión, pues fue atestiguado de María Madalena e mostrado a ella antes que a otra alguna persona, salvo a su gloriosa Madre. E de Santa Ysabel quiso fuese atestiguada su santa Encarnasçión. E de otras bienaventuradas mugeres quiso ser loado e manifestado por Dios e por Señor como lo es"' (ibid.). Así, pues, la Madre Juana no constituye un caso excepcional.

Una respuesta más oblicua a la misma pregunta se halla en la actitud antiintelectual que se vislumbra de vez en cuando en el Libro del conorte. Al comienzo del sermón para la fiesta de San Francisco, Cristo da gracias al Padre por haber escondido sus secretos a los "letrados e sabios" y habérselos revelado a los sinples e despreciados y humilldes" (fol. 369v; cf. Lucas, 10:21). Aunque es

14 En dos lugares (fols. $28 \mathrm{r}$ y $31 \mathrm{v}$ ), la Vida manuscrita cuenta cómo cierto inquisidor incrédulo asistió a uno de los sermones y acabó convencido de que las palabras de la Madre Juana tenían origen divino.

15 Santa Teresa, Obras completas, ed. Efrén de la Madre de Dios, O.C.D., y Otger Steggink, O.C., $7^{\text {a }}$ ed., B.A.C., Madrid, 1982, pp. 64, 183, 400 y 412. 
obvio que esto se aplica al Pobrecito de Asís, también se da a entender que la Madre Juana es una de esas almas humildes y simples. Y en otro lugar (sermón sobre las penas del infierno, fol. $407 \mathrm{v}$ ) dice Cristo que a veces, por permisión suya, los letrados leen las Escrituras sin entenderlas, y luego hace que "las oigan dezir [a] algunas personas simples, y entonces las entienden mejor", de manera que no hay que despreciar a quien diga la palabra de Dios "con caridad e amor de los próximos e deseo de su salvación'". Así, pues, se justifica el derecho de la Madre Juana a pronunciar sermones a pesar de no ser predicador $^{16}$.

La idea de que Dios revela sus misterios a los humildes, y entre ellos a las mujeres, se tomaba muy en serio en la España de Cisneros ${ }^{17}$. La mayoría de los visionarios protegidos por el cardenal eran mujeres, y él mismo les pedía consejos y hacia caso de sus mensajes. Fin tal ambiente cabia la posibilidad de que algunas mujeres se apropiaran el papel sacerdotal - masculino- de predicador y mediador ente Dios y el genero humano, introduciendo alteraciones en la estructura jerárquica de la lglesia como conducto único de la gracia. Pero a los críticos que hubieran expresado ese temor podía habérseles respondido que las visiones de la Madre Juana de ningún modo minaban la autoridad de la Iglesia. Y, en efecto, bajo la superficie de revelaciones a veces extravagantes yace una doctrina religiosa de lo más ortodoxo. Con su insis-

16 He aquí la declaración de fray Juan Hurtado, uno de los testigos en el proceso inquisitorial (1509) de María de Santo Domingo (la "Beata de Piedrahita"): "Interrogatus si la dicha soror María oye confesiones de algunos, dixit que ha oído, y no sabe a quién, que la dicha soror María oye confesiones, pero no sacramentaliter, y también ha hecho uno o dos sermones, pero no como a sermonadores, el uno en Viloria y el otro en Piedrahita" (VICENTE BELTRÁN DE HeREDiA, O.P., Historia de la reforma en la provincia de España, Istituto Storico Domenicano, Roma, 1939. pp. 113114). Años después, durante el proceso de María de Cazalla, Pedro Ruiz de Alcaraz censuró (1533) sus pláticas sobre pasajes bíblicos, declarando que "la dicha María de Caçalla se entremetía en hablar cosas de la Sagrada Escriptura que a ella no era lícito hablarlas por ser muger" (Milacros ORTECA COSTA, Proceso de la Inquisición contra María de Cazalla, Fundación Universitaria Españolá, Madrid, 1978, p. 188). En 1575 los detractores sevillanos de Santa Teresa acusaron a las descalzas de asumir eí papel sacerdotal de confosor: dijeron "que se confesaban unas con otras, tomando ocasión de la regla que dice la Madre, que las monjas den cuenta a las prioras de su espíritu" (Peregrinación de Anastasio, diálogo XIII, en Obras del P. Jerónimo Graciám de la Madre de Dios, ed. Silverio de Santa Teresa, El Monte Carmelo, Burgos, 1933, t. 3, p. 201).

17 En la defensa que hizo fray Antonio de la Peña durante el proceso (1509) de Sor María de Santo Domingo se lee: "Que la dicha soror María in suis raptibus algunas vezes suele responder a preguntas grandes, ansý en theología, en profundos artículos, como en cosas de la Sagrada Escritura y en cosas pertenecientes a nuestra santa fee cathólica y a buenas costumbres, y de la gloria del paraíso y de las penas del infierno y del purgatorio y de los santos sacramentos, pero no a cosas vanas y curiosas y que son sin perversión de las almas. Fn tal manera, que a los que ansí la veen y oyen responder parece cosa muy maravillosa que una pobre mugerçilla ignorante, como es la dicha soror María, y criada en aldea, responda tan bien y aun algunas vezes mejor que qualquier maestro de Theología y hombre de gran ciencia" (BERNARDINO LLORCA, La Inquisición española y los alumbrados, 1509-1667, refundición y puesta al día de la ed. de 1936, Universidad Pontificia, Salamanca, 1980, pp. 262-263). En el prólogo del Libro de la bienaventurada Sancta Ángela de Fulgino (Toledo, 1510), traducción encargada por Cisneros e impresa con su escudo, dice el traductor: ". . . paresce que en esta muger fuerte claramente se muestra lo que estava abscondido aun a los varones muy especulativos, pero ciegos con sus carnales exposiciones y entendimientos"; y después de observar cómo, "en menosprecio e para confusión de los varones carnales", a veces ha dispuesto Dios que las mujeres enseñen a los varones, compara a Santa Ángela con la profetisa Holda (IV Reyes, 22:14), "a la qual recurría el pueblo en opprobio e denuesto de los varones e doctores de la ley, que por ser quebrantadores e traspassadores de los mandamientos, la prophecía fue traslada a sexo femíneo" (fol. l r-v). No cabe duda de que Cisneros veía en la Madre Juana una segunda Holda, una segunda Santa Ángela. 
tencia en la veneración de la Eucaristía y en la necesidad de la penitencia, la autora afirmaba su propia ortodoxia y, a la vez, el papel indispensable del clero en la administración de los sacramentos. La defensa del propio derecho a cumplir una función sacerdotal, la predicación, desembocaba en un reconocimiento de que las demás funciones les estaban vedadas a las mujeres, o sea en una afirmación de la jerarquía eclesiástica privativa de los varones.

Otro aspecto de los sermones de la Madre Juana que se defiende desde dentro es la novelización de los relatos evangélicos. La amplificación del texto sagrado con detalles que no figuran en él era una característica de la espiritualidad franciscana ${ }^{18}$. Pero, aquí y allá, la Madre Juana se muestra preocupada por la posibilidad de que alguien la acuse de estar novelando, y entonces explica por qué lo que ella cuenta no figura en ninguno de los cuatro evangelios. En primer lugar, era imposible que los evangelistas apuntaran todas las palabras de Crista (fol. 334r). Así, despuxés de que Criso (en el semón para Pascua de Resurrección, fol. 163r) cuenta que las heridas de la Pasión seguían sangrando aún después de la Resurrección, y que los apóstoles, para restañar la sangre, aplicaron a las heridas paños empapados en agua fría, se añade que los evangelistas no consignaron esta circunstancia porque "no quisieron dezir otra cosa sino lo que fazía al caso e convenía para nuestra fe". En otro lugar (sermón para la fiesta de Santa Ana, fol. 289v) cuenta Cristo que, siendo de edad de dos o tres años y llevándolo en brazos Santa Ana, les reveló a ella y a la Virgen María ciertos secretos y misterios. Ninguna de las dos se los comunicó a nadie, pues no era función que les incumbiera; y en cuanto a los evangelistas, cuyo cometido era relatar los hechos de la vida pública de Cristo, no escribieron ni la décima parte de lo que pasó. Por cierto que cuando Santa Ana cargaba en brazos a su divino Nieto, era favorecida con visiones del cielo y de la Trinidad no muy distintas de las que experimentaba la monja. Esa Santa Ana vidente es un claro alter ego de la Madre Juana. Además, la revelación divina se complementa mediante la monja, pues es ella quien comunica al mundo lo que nunca reveló Santa Ana.

El sermón para el Miércoles Santo amplifica notablemente el cpisodio del ángel que se apareció a Cristo en Getsemaní para confortarlo (Lucas, 22:43). En realidad fueron varios los ángeles que se le aparecieron, rogándole que no sufriera la Pasión, y entonces Él les mostró una "figura", una especie de cuadro plástico cuyas alegorías demostraban la necesidad de la Crucifixión. Y Cristo explica que no quiso en aquellos momentos darle a conocer a nadie esa visión, "porque aquel tienpo en que Él entonçes estava hera más de humilldad e paçiençia e silençio e sufrimiento de injurias e tormentos e llagas e feridas que de dezir ni descubrir secretos ni visiones ni revelaçiones"' (fol. 141v). El sermón sobre el Perdimiento en el Templo nos ofrece otro caso aún más claro de revelación postergada. Hay en él muchos detalles que no aparecen en el

18 El texto más representativo y conocido de la tradición franciscana son las Meditationes vitae Christi, cuyo autor muestra, en el prólogo, estar muy consciente de que los episodios de la vida de Cristo a cuya contemplación invita a los lectores no se encuentran necesariamente en el texto evangélico (cito por la traducción del siglo Xv, Contenplaçión de la vida de Nuestro Señor Jesuchristo, B.N.M., ms. 9560, fol. 3r): "Mas mayor esperança tengo que si en estas cosas ouieres exerçitarte con prudente contemplaçión, que tendrás por maestro a Nuestro Señor Jesuchristo de quien hablamos, no porque estén escriptas todas las cosas que podemos contemplar que Él hizo y dixo, mas por que mejor se puedan ynprimir. Assý te las contaré yo como si assí oviesen sydo de la manera que acaesçieron o se puede creer piadosamente que acaesçieron, segund algunas representaçiones de la ymaginaçión". 
evangelio, y Cristo mismo dice que si los evangelistas no hicieron un relato circunstanciado fue por dos razones: primera, porque no fueron testigos oculares de los hechos de la niñez y mocedad ( $y$, después, no se informaron de todo lo ocurrido en esos años); y segunda, porque no tuvieron tiempo más que para consignar una parte de los misterios sagrados, y, aun así, sólo escribieron lo que más estrechamente se relacionaba con la salvación de las almas. Pero ahora, en tiempos de la Madre Juana, Dios ha determinado revelar lo que faltaba, para que todos sepan "quánto ama a las ánimas e desea su convertimiento e salvación' (fol. 112v). Un caso parecido es el del sermón, sumamente novelesco, sobre la Creación de los Ángeles y la Caída de Luzbel. Observa Cristo que, aunque algo se ha escrito "acá" (en la tierra) sobre tan grandiosos acontecimientos, queda todavía mucho por decir, puesto que quienes los describieron no fueron testigos oculares. Él, Cristo, fue testigo ocular, como que fue Él quien creú a los ángeles "e derribó a los que erraron contra Él" (fol. 362v). Se da a entender que el relato contenido en el sermón es más completo y exacto que ningún otro, puesto que es la versión de Dios mismo, todo lo cual venía a constituir una respuesta a las posibles críticas. No era que la Madre Juana amplificara por su cuenta, sino que compietaba la revelación divina. Ella no hacía más que revelar, por orden de Dios, lo que los escritores sagrados no quisieron o no pudieron registrar.

En verdad, la Madre Juana de la Cruz nació en buena hora. De haber nacido a comienzos del siglo XV, quizá se la habría acusado, como se acusó a Teresa de Cartagena, de inmiscuirse en negocios espirituales que sólo competían a varones ${ }^{19}$. De haber nacido a comienzos del XVI, de seguro habría tenido problemas con la Inquisición, como los tuvo Teresa de Ávila ${ }^{20}$. Vivió, por suerte, en una época muy favorable a toda clase de fenómenos religiosos extraordinarios ${ }^{21}$. La cuestión del curato de Cubas demuestra los límites de la autoridad femenina en asuntos de jurisdicción aclesiástica, pero es un hecho que en tiempos de Cisneros se tenía una alta opinión del papel de las mujeres visionarias. Ahora bien, si la protección del cardenal resolvió o impidió ciertos

19 La Admiraçión operum Dey es respuesta a las críticas que se le hicieron por haber escrito una obra de espiritualidad. Véase TERESA DE CARTAGrNA, Arboleda de los enfermos. Admirafión operum Dey, Madrid, 1967 (anejo 16 del BRAE), pp. 111-141.

20 Véase Enrique Llamas MarTínez, Santa Teresa de Jesús y la Inquisición española, C.S.I.C., Madrid, 1972. Conocido es el cambio brusco en el clima espiritual de España a partir de 1559, año del auto de fe de los protestantes de Valladolid, la prisión del arzobispo Carranza y el Índice de libros prohibidos de Valdés. La Inquisición acabará por calificar de "ilusas" a todas las beatas y visionarias. Véase CLAIRE GUILHEM, "L'Inquisition et la dévaluation des discours féminins", apud Bartolomé Bennassar (ed.), L'Inquisition espagnole, xjexix siècle, Hachette, Paris, 1979, Pp. 197-240. Sobre las sospechas especiales que suscitaban las mujeres videntes, véase JuLIO CaRO BAROjA, Las formas complejas de la vida religiosa, Akal, Madrid, 1978, pp. 40-42.

21 En la traducción castellana del Tratado de la vida espiritual de San Vicente Ferrer, Toledo, 1510, impresión patrocinada por Cisneros, se suprimen los capítulos en que el santo valenciano pone en guardia contra las revelaciones. Véase Álvaro HuERGA, "La edición cisneriana del Tratado de la vida espiritual y otras ediciones del siglo xvl", Escritos del Vedat, 10 (1980), 297-313. La desvalorización de los fenómenos extraordinarios a partir de 1559 salta a la vista en la censura del Catechismo de Carranza hecha por los maestros Cano y Cuevas, donde se alude justamente al pasaje de San Vicente Ferrer omitido en la edición cisneriana: "Estos raptos llamó Sant Biçente, prophetizando lo que avía de venir, rauiamientos, con los quales e otras illusiones semejantes se avía de disponer el mundo para el Antechristo. E aunque alguna vez se pueda poner exemplo en algunos sanctos de estos arrebatamientos, ni son exemplos de imitar ni de proponer al pueblo, mayormente en el tiempo presente. . ' U. Ignagio IDÍGORAs, Fray Bartolomé Carranza: Documentos inéditos, t. 6, Real Academia de la Historia, Madrid, 1981, p. 325). 
problemas externos, a la Madre Juana le quedó la tarea de ocuparse por cuenta propia de la cuestión de la autoridad, y lo que hizo fue incorporarla al texto de sus sermones. Resulta entonces que la propia experiencia mística es lo que le confiere autoridad para predicar. Es Cristo quien ha querido hablar a través de ella para lograr la salvación de los hombres y para completar su revelación. Así, pues, la experiencia mística le permitió a la Madre Juana hacer a la vez el papel lícitamente femenino de visionaria y el papel canónicamente masculino de predicador, de autor de sermones ${ }^{22}$. Pese a su falta de rango sacerdotal y de saber formal, pudo ejercer una función pastoral negada en principio a la mujer.

RONALD E. SURTZ

Brinceton Uxiversity

\section{GILMAN SOBRE GALDÓS UNA APROXIMACIÓN A SU LIBRO MÁS RECIENTE}

Con la publicación de Galdós and the art of the European novel: 1867-18871, Stephen Gilman corona largos años de labor crítica en torno al novelista canario. El libro - aportación seminal a los estudios galdosianos - recoge, considerablemente ampliados y ordenados de manera coherente para articular una hipótesis novedosa, trabajos publicados en Anales Galdosianos (1966, 1970, 1976́, 1978), la Nueva Revista de Filologia Hispánica (1949, 1961, 1975), la Revista Hispánica Moderna (1968), Estudios literarios de hispanistas norteamericanos dedicados a Helmut Halzfeld (1974) y Les culiures ibériques en devenir: Essais publiés en hommage à la mémoire de Marcel Bataillon (1979).

Desde el momento en que Dorio de Gádex lo marcó con el epíteto de "don Benito el garbancero" en Luces de Bohemia, la suerte de Galdós ante la crítica ha sufrido altibajos singulares. Acusado de "vulgar" y de "carecer de estilo" (como en su momento Dostoievski e incluso Joyce) por sus coetáneos ValleInclán y Unamuno - entre los generacionistas del 98 es excepción el fervor entusiasta de Azorín - fue ignorado por la oficialidad literaria del régimen franquista, que no le perdonó ni su secular liberalismo ni las manifestaciones de adhesión socialista de los últimos años. A la crítica norteamericana -en la que Gilman ocupa el puesto más destacado- debemos la reivindicación

22 De hecho, aunque las revelaciones de la Madre Juana se presentan como "sermones", carecen totalmente de la estructura típica del sermón medicval, con su técnica homilética de divisiones y subdivisiones. En los sermones de la Madre Juana no hay prácticamente nada de exégesis escrituraria; lo que hay en su lugar son alegorías triviales. Lo grueso de ellos consiste en una amplificación novelada de los relatos evangélicos, seguida de la descripción (con glosas) de las fiestas alegóricas celebradas en el cielo. Aunque inspiradas en el relato evangélico, esas descripciones no pueden considerarse explicación del texto sagrado.

1 Princeton Umiversity Press, Princeton, 1981. 